\title{
ARQUITETURA PAISAGÍSTICA: UM ESTUDO SOBRE REPRESENTAÇÕES E MEMÓRIA - ESTUDO DE CASO: PRAÇAS DA CIDADE DE PELOTAS - 1860-1930
}

\author{
LANDSCAPE ARCHITECTURE: A STUDY ABOUT REPRESENTATION AND MEMORY CASE \\ STUDY: SQUARES IN PELOTAS - 1860-1930
}

\author{
MATTOS, Maria Regina de \\ Arquiteta paisagista e professora da Faculdade de Arquitetura e Urbanismo da Pontifícia Universidade \\ Católica do Rio Grande do Sul - Porto Alegre-RS. \\ E-mail:mmatos@pucrs.br
}

\section{RESUMO}

Este trabalho dedica-se a apreciar o conceito de paisagem urbana, tentando desvendar as complexas tramas que envolvem as relações dos seres humanos com a natureza, bem como a construção da paisagem destes lugares.

Também o trabalho tem como objetivo o estudo dos principais espaços públicos urbanos, representados pelas praças centrais da cidade de Pelotas (1860 a 1930). Nesta época a crescente ocupação urbana, produzida pela prosperidade econômica, mudanças sociais e culturais, conduziram à organização espacial da cidade, representada pela malha urbana e edificações arquitetônicas. Os usos e as formas compositivas das praças em estudo, mantêm uma relação estrita, recíproca para a configuração de uma identidade urbana própria.

\section{Palavras-chave: Prosperidade, espaços públicos, natureza, apropriação.}

\begin{abstract}
The analysis of the urban space concept that these areas embody, this study aims to understand the complex relationship between people and nature e established in these spaces.

This investigation is to study the public urban areas that are represented by the squares locateds in the central area of the city of Pelotas (1860 and 1930). At that time, the economic prosperity provoked a significant urban growth, together with the spatial organization of the buildings and the streets helped to influence the final shape of the areas, and de consequent appropriation of these squares by the users.
\end{abstract}

Key words: Prosperity, public spaces, nature, appropriation.

No final do século XIX, começo do século XX, o mundo passava por grandes transformações, advindas da era industrial, da descoberta de novas tecnologias, do crescimento exagerado dos núcleos urbanos, das mudanças de comportamento e de hábitos das populações que moravam nas cidades. Esses fatores vão refletir diretamente no desenho do espaço físico e do modo de habitar das cidades.

Espaços identificáveis e figurativos como as praças adquirem uma importância fundamental, como espaços de identidade para quem habita as cidades. Os centros urbanos foram desenhados segundo a ótica das pessoas que se deslocavam a pé e mais tarde de carro, percurso de zonas de compressão e de vazios, contraste entre espaços amplos e espaços delimitados, alternância de tensões e de tranqüilidade. As praças tomam seu papel de importância como espaço físico, no momento em que são consideradas como ilhas de descompressão dentro do desenho urbano. Paulo Zucker' caracterizou-as como "lugar de estacionamento psicológico dentro da paisagem cívica".

Como espaços de representação, as praças das cidades modernas têm um papel fundamental para o equilíbrio das pessoas, pois a natureza, agora distante, é reportada para esses espaços 
de modo ordenado, domesticado, belo e sem os perigos da natureza selvagem. A natureza transportada para os jardins das praças, numa representação simbólica, pode ser usufruída pelo homem, mas como algo impalpável, invisível, não materializado como se estivessem no "Jardim do Éden". O homem tem procurado a simbologia do ambiente natural de forma constante nos seus sonhos, como um mundo ideal, e a construção desse mundo ideal é uma questão de remover os defeitos do mundo real, criando "ilhas" dentro da malha urbana. As árvores guardam, no seu interior, os mistérios da natureza, que não podem ser desvendados totalmente.

A paisagem não é estática, pois todos os elementos nela contidos se modificam constantemente, ou pela ação do tempo, ou pelo homem. Um território é formado por um número infinito de paisagens facilmente justapostas, e a essas paisagens conferimos um determinado significado estético, cultural, científico ou social. A sistematização, consciente ou intuitiva, desses elementos é que nos permite evocar a "terra natal", em contraposição a todas as outras que serão conhecidas.

Ao longo do século XIX, relatos são produzidos de forma a se constituírem a memória de grupos sociais desta época. Maurice Halbwachs estabeleceu uma analogia entre território do grupo e sua memória, a partir da qual destaca três questões:

1) As formas organizadas do espaço não são apenas um quadro ou um suporte da lembrança ou o meio de sua cristalização;

2) o grupo mantém com seu espaço o mesmo tipo de relação que mantém com seu passado;

3) o que vale para a produção de memória vale para a produção do espaço e reciprocamente ${ }^{2}$.

Valendo-nos desses conceitos, utilizamos a memória para procurar reelaborar os espaços e desses espaços recriamos a memória. As sociedades urbanas procedem continuamente a uma reatualização e a mudanças; o passado não ressurge idêntico, mas, a cada etapa de seu desenvolvimento, as sociedades remanejam as suas lembranças de forma a adequá-las às condições do momento de seu funcionamento.

Entendemos como lugares de memória a crônica e a história social, cultural e política de uma sociedade. Elas tecem uma relação com o espaço e a memória de um lugar, estabelecendo territórios e tempos.

Maurice Halbwachs, na obra A memória coletiva, escreve:

"O espaço possui, em relação à memória, um duplo estatuto. Primeiramente, ele inscreve-se na mesma relação dialética do social em geral: por um lado, a memória coletiva apóia-se em imagens especiais; por outro, desenhando sua forma no solo, os grupos sociais definem seu quadro especial, nele inserindo suas lembranças. Em segundo lugar [...] apenas a imagem do espaço, graças a sua estabilidade, é que nos dá a ilusão de não mudar através do tempo e de reencontrar o passado no presente."

O espaço urbano e a memória coletiva dos grupos sociais que o ocupam estão ligados e comportam uma mesma análise. A memória expõe o passado com base no presente e o espaço ocupa seu lugar, mas não de forma idêntica. A sociedade remaneja suas lembranças de modo adequá-las às condições do momentos e para satisfazer suas necessidades.

Para estudarmos as praças, alguns pontos são fundamentais para podermos entender esses espaços.

232 Em primeiro lugar, devemos conhecer a história da formação dos espaços, as mudanças sofridas ao longo do tempo e as razões das mudanças, ou seja, a história desses espaços através do tempo. Como a praça vincula-se fortemente ao lugar ao qual ela pertence, é fundamental a compreensão desse lugar, mais do que a da forma ou da paisagem em si, senão estaremos estabelecendo um sistema fechado de análise. 
Em segundo lugar, estudar os monumentos (prédios) e as ruas que delimitam esse espaço e que Ihe servem de cenário e os visuais decorrentes da formação destes espaços.

"As fachadas arquitetônicas são as divisórias entre o espaço particular (do proprietário) e o espaço comum (espaço comum), o limite entre o privado e o público, entre o individual e o social. Essas fachadas, porém não só determinam esses dois espaços distintos - espaço interior arquitetônico e o espaço urbano - mas os qualificam, valorizam e caracterizam. [...] Também atuam como reflexo da mentalidade de uma sociedade, de uma determinada época e local, quando analisada em seu conjunto."

Em terceiro lugar, conhecer a história dos usos dos espaços delimitados por uma sociedade em um determinado tempo e de seus comportamentos sociais, através das crônicas, que são estórias narradas e derivadas da percepção do viver cotidiano desses grupos, num certo lugar, num ir e vir do passado/presente. Margarida de Souza Neves escreve: "Na forma como no conteúdo, na seleção que efetua como na linguagem que emprega, a crônica é sempre e de forma muito distinta, um texto que tematiza o tempo e, simultaneamente, o mimetiza. Tal como a história, aliás." ${ }^{15}$

E por último, o estudo do espaço físico da praça desde a sua implantação até sua consolidação. Para tal análise, aplicaremos a metodologia que Louis Marin utilizou para "ler" um quadro e que podemos utilizar para "lermos" os espaços das praças, como o seu traçado, o estilo dos seus jardins, seus equipamentos e monumentos (estatuária) e a vegetação existente.

Assim, como essa análise, podemos ter um entendimento do espaço físico ocupado pela praça e do perfil dos grupos que a utilizaram e que fazem parte da história da cidade.

"O homem tem em todos os momentos a percepção de sua posição relativa, sente a necessidade de se identificar com o local em que se encontra, e esse sentido de identificação, por outro lado, está ligado à percepção de todo o espaço circundante."

Lovis Marin ${ }^{7}$ parte de critérios que possibilitam a transposição do registro da imagem ao registro da fala e da escrita. Segundo esse autor, há três modalidades para se "ler" e "decifrar" uma obra de arte, ou, no caso, a praça. Na primeira, trata-se do percurso com o olhar, realizado num trajeto ordenado, dentro dos limites do quadro, como sistema fechado. Esta primeira modalidade constitui, na arquitetura, a "visão serial" segundo Gordon Cullen, isto é, a visão do percurso de uma pessoa ao atravessar determinado espaço de uma cidade pela primeira vez. Ela percorre ruas que desembocam nos espaços de praças, que darão em novas ruas, e assim sucessivamente.

A paisagem urbana surge, na maioria das vezes como uma sucessão de surpresas ou revelações súbitas, ora agradáveis, ora não, e essas sensações primeiras são as que ficam gravadas na memória das pessoas em relação a uma determinada cidade ou lugar. $A$ isso chamamos de "visão serial", e ela vai ajudar a decifrar e gravar na memória os espaços de uma cidade.

Numa perspectiva visual, temos dois pontos a considerar: a imagem existente, aquela que vemos, que é real; e a imagem emergente, que é uma sucessão de acontecimentos fortuitos, e suas ligações não passam de mera coincidência. Da junção das duas, isto é, a partir da realidade inerte, podemos criar uma situação intensamente emotiva, como quando olhamos um quadro, representação inerte e ao mesmo tempo dinâmica, pois tem o poder de mexer com o sentimento das pessoas que o olham.

Ele, o usuário, percebe elementos determinados, em um demarcado espaço sem se preocupar propriamente com os elementos que esse espaço contém e com nossas reações ante a nossa posição nesse espaço, que Gordon Cullen chama de "local", isto é, como "estou fora", estou a entrar ali "para dentro", ou "estou aqui dentro". É nesse tópico que podemos analisar a apropriação do espaço, território ocupado ou livre, apropriação do movimento, recinto, circulação 
de pessoas e de veículos, unidades urbanas, pontos focais, paisagem interior e comportamento exterior, recintos múltiplos, delimitação dos espaços e vistas para o exterior, focalização, perspectivas, delimitações, barreiras, pavimentações.

Numa segunda modalidade, segundo Louis Marin, fundamentada na primeira, o olhar reconhece, nas figuras expostas, a história que ele conhece de outra maneira, como duplo processo de iconização de um texto escrito e de textualização de uma disposição figurativa. Aqui nos transportamos novamente para a arquitetura paisagística, como o item "conteúdo", isto é, a própria constituição do espaço a ser estudado, como sua cor, a textura, a escala, o estilo a que pertence, a sua natureza, a sua personalidade e tudo o que o individualiza, isto é, a que categoria pertence - a praça central, a de periferia, etc, seus pormenores (gradeamento, degraus, etc.), objetos significativos, geometria, obras edificadas, como esculturas, seus contrastes, seus usos, sua escala em relação à cidade, sua história e sua integração com as árvores, enfim todos os elementos que compõem esses espaços e seus significados.

Na terceira modalidade, a contemplação torna-se repetição diversificada de percursos de visão e percursos de "leituras". Novamente, nos transportamos para os espaços abertos.

A cidade passa a ser uma experiência eminentemente plástica, percurso através de zonas de compreensão e de vazios e contrastes entre espaços amplos e espaços delimitados.

Depois da análise feita e da "leitura" dos espaços, temos condições de voltar novamente a "passear" por esses espaços e de ter uma nova visão e nova "leitura", visibilidade e legibilidade, em harmonia num sistema fechado.

\section{Estudo de caso}

No lugar onde se estabeleceu a cidade de Pelotas no Rio Grande do Sul, a paisagem era de um relevo quase plano, ao nível do mar, clima úmido e com pouca vegetação, principalmente de grande porte. A paisagem natural estendeu-se para a paisagem urbana, onde as ruas que compunham essa paisagem eram desprovidas de arborização. As praças foram adaptadas aos modelos europeus nos seus traçados, e "enfeitadas" com vegetação exótica, de preferência de pequeno porte, e com flores, não como forma de compor a paisagem, mas para demonstrar um status cultural trazido da Europa.

A praça-jardim tornou-se um ícone social do espaço urbano e passou a ser vista e representada por elementos como canteiros ajardinados, fontes, quiosques e coretos e situada no centro, zona da elite da cidade.

Seguindo o conceito de que as praças são indissociáveis do lugar, tornou-se índice de civilidade e de qualidade de vida urbana tratá-las adequadamente, embelezando e melhorando seus espaços físicos. Com esses procedimentos, Pelotas estava no mesmo nível das principais cidades brasileiras e européias modernas quanto ao tratamento de seus espaços urbanos.

Nas cidades modernas, as praças, geralmente em estilo historicista eclético, foram espaços de segregação social, onde os mais abastados as freqüentavam em detrimento do povo, onde havia uma rígida forma de comportamento. Passear na praça exigia trajes adequados e comportamento cortesão, típicos da belle époque. As praças brasileiras, entre elas as de Pelotas, em decorrência das fortes influências européias, adotaram esse comportamento, excluindo aquelas pessoas menos privilegiadas. Somente a partir da década de 1920, quando se iniciou um movimento cultural moderno, houve uma mudança no modo comportamental da sociedade, influindo diretamente nos usos dos espaços urbanos. Surgiu uma classe média, composta por comerciantes, pequenos burgueses, e uma classe menos privilegiada, a dos trabalhadores; as classes sociais misturam-se, mas todos deviam estar integrados aos novos padrões da sociedade dita moderna, utilizando suas horas de folga, principalmente o lazer de fim de semana, 
em passeios aos locais das praças e parques, acompanhados por suas famílias, como forma de sociabilidade e ascensão social.

O processo de urbanização de Pelotas, situada no sul do estado do Rio Grande do Sul, deu-se de forma rápida e ordenada. A cidade estabeleceu, desde o seu começo, normas de conduta, com o código de posturas, regras de administração, criando leis municipais, disciplinando a vida da comunidade e leis urbanísticas, organizando e estruturando a cidade. $O$ resultado foi a caracterização espacial bem determinada desde sua implantação, como os lotes, profundos e estreitos, com as edificações ocupando toda a frente e junto à calçada, ruas mais largas no sentido norte-sul e mais estreitas, travessas, no sentido leste-oeste. As praças tinham dimensões estabelecidas, com todos os lados de iguais dimensões, e eram caracterizadas como espaços de passagem e de sociabilidade, um legado português.

O desenvolvimento da cidade de Pelotas teve seu auge no período de 1860 a 1900, quando houve recuperação econômica atrelada ao setor de produção, e os esforços para a construção de uma cidade moderna foram retomados. O desenvolvimento econômico gerou o desenvolvimento urbano. No mesmo período, houve um crescimento demográfico, resultando no aumento da malha urbana e na necessidade de novos espaços públicos para essa população. Praças foram criadas e as centrais delimitadas, equipadas e arborizadas, formando um continuum verde dentro da área central da cidade, com eixos visuais bem legíveis, dando condições ao indivíduo de deslocar-se, com pontos referenciais (as praças) sempre nos limites desejáveis.


Figura 1: Plano diretor da cidade de Pelotas

Fonte: SALENGE, Laís de P. (Org.). Plano Diretor de Pelotas, Prefeitura Municipal, 1967
Figura 2: Vista aérea da cidade, vendo-se, ao centro, a praça Cel. Pedro Osório

Fonte: Acervo do Projeto Pelotas Memória 
O mapa mental organizado com essas referências tornou-se suficiente para a identidade e a legibilidade urbana.

Pelo seu desenvolvimento crescente, resultante de um poder econômico, Pelotas rivalizava com Porto Alegre, a capital do Rio Grande do Sul, e seus espaços públicos eram semelhantes nas duas cidades, não só no número de praças existentes, mas no seu tratamento e nos equipamentos.

Nas duas cidades, o progresso chegou no mesmo período, como a iluminação pública, a modernização dos transportes e a implantação de infra-estrutura. A diferença entre as duas cidades era o modo como se deram transformações espaciais no começo do século XX. Em Porto Alegre, com o Plano de Melhoramentos e Embelezamento da Capital, houve "rasgos" no tecido urbano bastante significativos, enquanto em Pelotas essas mudanças basearam-se no slogan da época "conservar melhorando". Nada foi derrubado. As cinco praças estudadas, estão situadas na área central da cidade, distantes poucos quarteirões uma das outras, num eixo de coordenadas xy. São consideradas praças com traçado português, em estilo historicista eclético, com partido rígido, de tríade clássica básica, onde foram observadas a simetria e as regras acadêmicas de composição, organização axial dos caminhos, implantação de elementos urbanos, como chafarizes, bustos, etc., vegetação arbórea, na maioria exótica e arbustiva podadas, formando desenhos. Os projetos dos jardins eram baseados em modelos de ajardinamentos franceses e ingleses. A organização espacial é igual em todas as praças estudadas, assim como a maioria dos elementos nelas dispostos. Mas quais são os fatores que thes conferem graus de importância e as diferenciam uma das outras dentro dessa malha urbana?

Quando as transformações sociais ocorreram nas cidades modernas, a estratificação social já não era rigorosamente estável, iniciando-se processos acelerados de diferenciação entre as classes. As praças foram "divididas" em territórios, onde cada classe social ocupava o seu lugar. O fator sociabilidade foi determinante para a diferenciação dos usos dos espaços das praças. Outro fator foi o caráter simbólico. A praça principal deveria ser o reflexo dos poderes político, econômico, social e cultural da cidade; portanto, os prédios ao seu redor deveriam ser os de uma arquitetura mais elaborada e luxuosa, pertencentes à elite da sociedade pelotense e deveriam permanecer assim como sua história social e política. Os cuidados dos espaços de jardins eram constantes e deveriam estar sempre em boas condições.

A praça Coronel Pedro Osório, a principal da cidade, foi sempre a representante do poder, pois ao seu redor estavam a maioria dos prédios arquitetônicos administrativos, os prédios culturais e de sociabilidade, bem como os casarões residenciais pertencentes a importantes e tradicionais famílias pelotenses. $O$ pelourinho foi instalado junto com a implantação da praça, como demonstração de poder político. Os equipamentos eram os mais suntuosos possíveis, como o magnífico chafariz instalado no seu centro vindo da França, chamado de "Fonte das Nereidas", e complementando o espaço um belo piso de ladrilhos e grandes áreas ajardinadas, numa demonstração de poder econômico e cultural, servindo para uma elite da sociedade. Durante muito tempo serviu de cenário para as principais manifestações públicas, tanto políticas onde dirigentes discursavam para um público seleto, para reuniões sociais que começavam na praça e iam terminar dentro dos majestosos casarões situados ao seu redor, ou para inauguração de algum monumento público. Era a praça da sociedade e da sociabilidade.

No mesmo eixo da praça Coronel Pedro Osório ficava a pequena praça da Matriz, hoje José Bonifácio, que servia de adro da Catedral. Antes, quando Pelotas ainda era vilarejo, possuía um chafariz, cumprindo a função prática de abastecimento d'água e ponto de encontro da gente do lugar. Escravos, ao buscarem água para o abastecimento das casas de seus senhores, traziam também as novidades. À tarde, era a vez dos senhores respeitáveis se encontrarem para tratar de negócios e de política. Festas religiosas e quermesses aconteciam na recém ampliada igreja. Era uma praça de grande importância social para a cidade. 


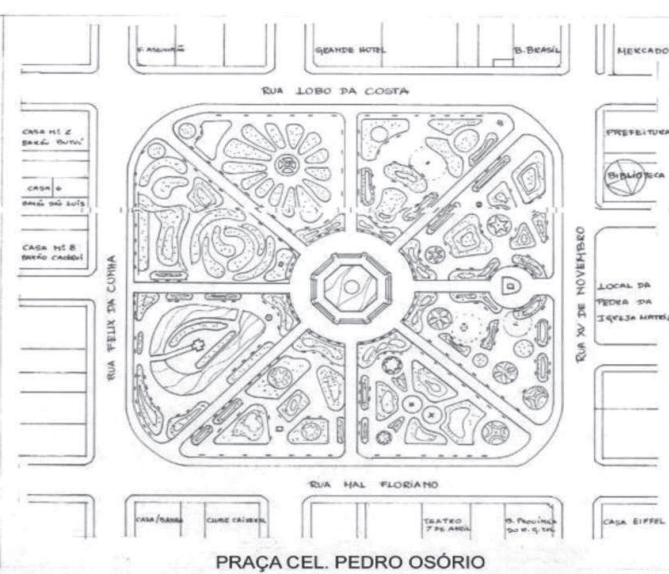

Figura 3: Planta baixa da praça Cel. Pedro Osório

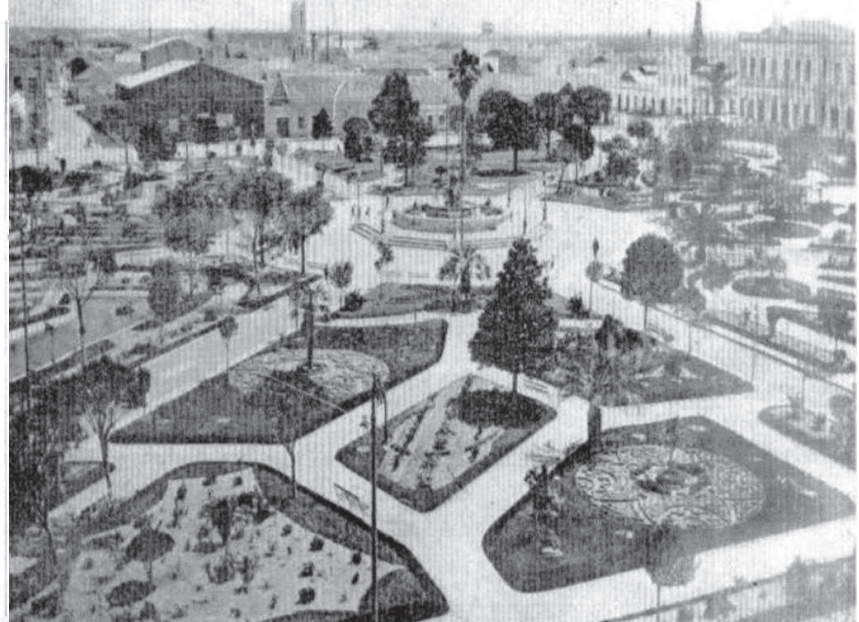

Figura 4: Jardins da praça da República, 1919 Fonte: Reprodução do original no Relatório do Intendente Cypriano Barcellos

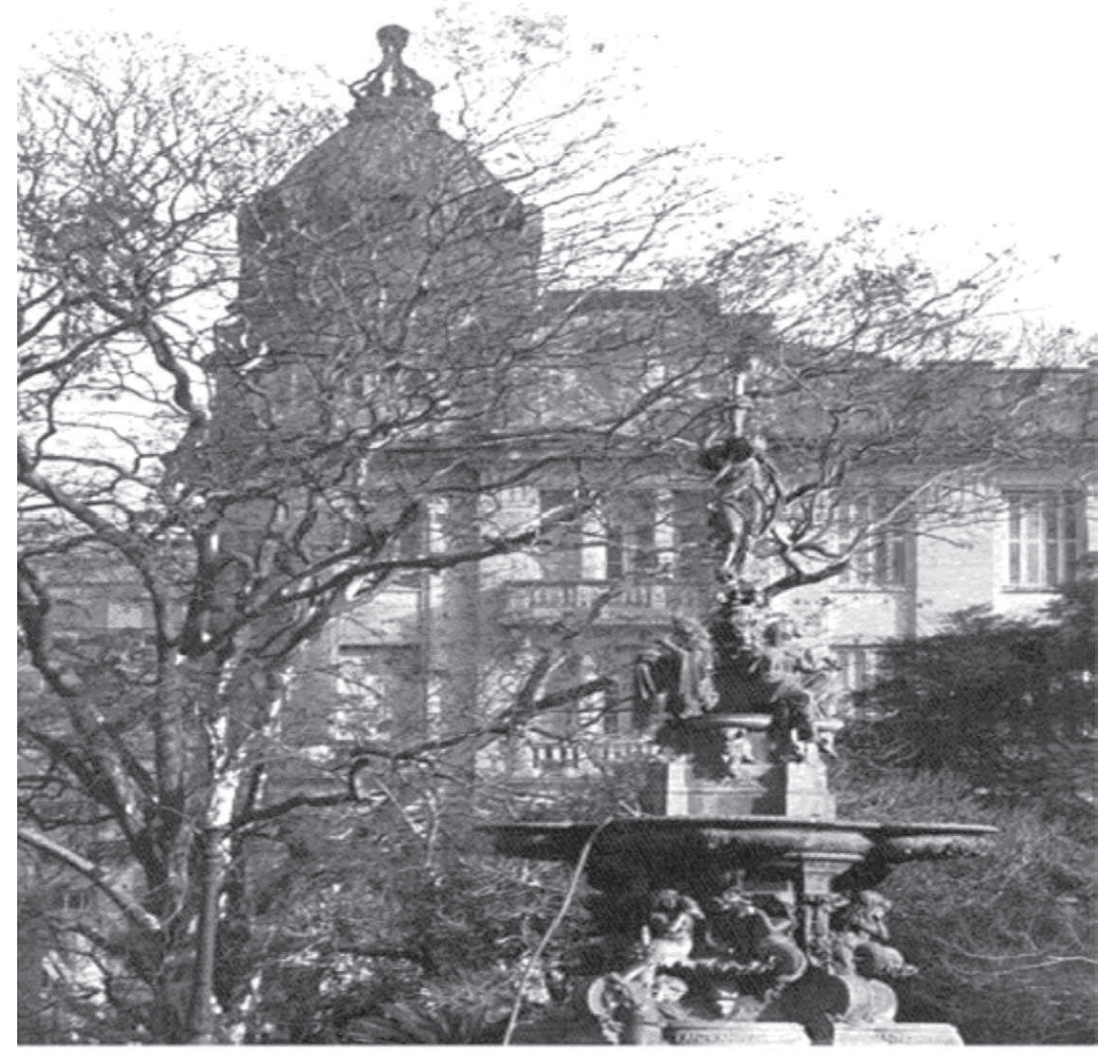

Figura 5: Praça Cel. Pedro Osório

Crédito: Foto de Neco Tavares, 2000

A cidade foi crescendo e se modificando. Pessoas importantes que moravam ao redor da praça da Matriz foram morar na praça da República, onde o poder político estava agora instalado. A aparência da praça da Matriz também foi mudando. Não possuía mais o chafariz. Pessoas e festas tornavam-se cada vez menos freqüentes. $O$ ponto principal era, agora, somente o busto de José Bonifácio.

No final desse eixo, estava a praça Júlio de Castilhos que, por ser uma praça situada nos limites do antigo traçado da cidade, foi, durante muito tempo, considerada periférica. Desde sua implantação, o tema educação está presente. Estavam localizados no seu interior uma pequena escola, um minizoo e o primeiro kind-garden, ou seja, uma pracinha de recreação infantil, que permanece até os dias atuais. Foi densamente arborizada, pois, no começo do século XX, pen- 

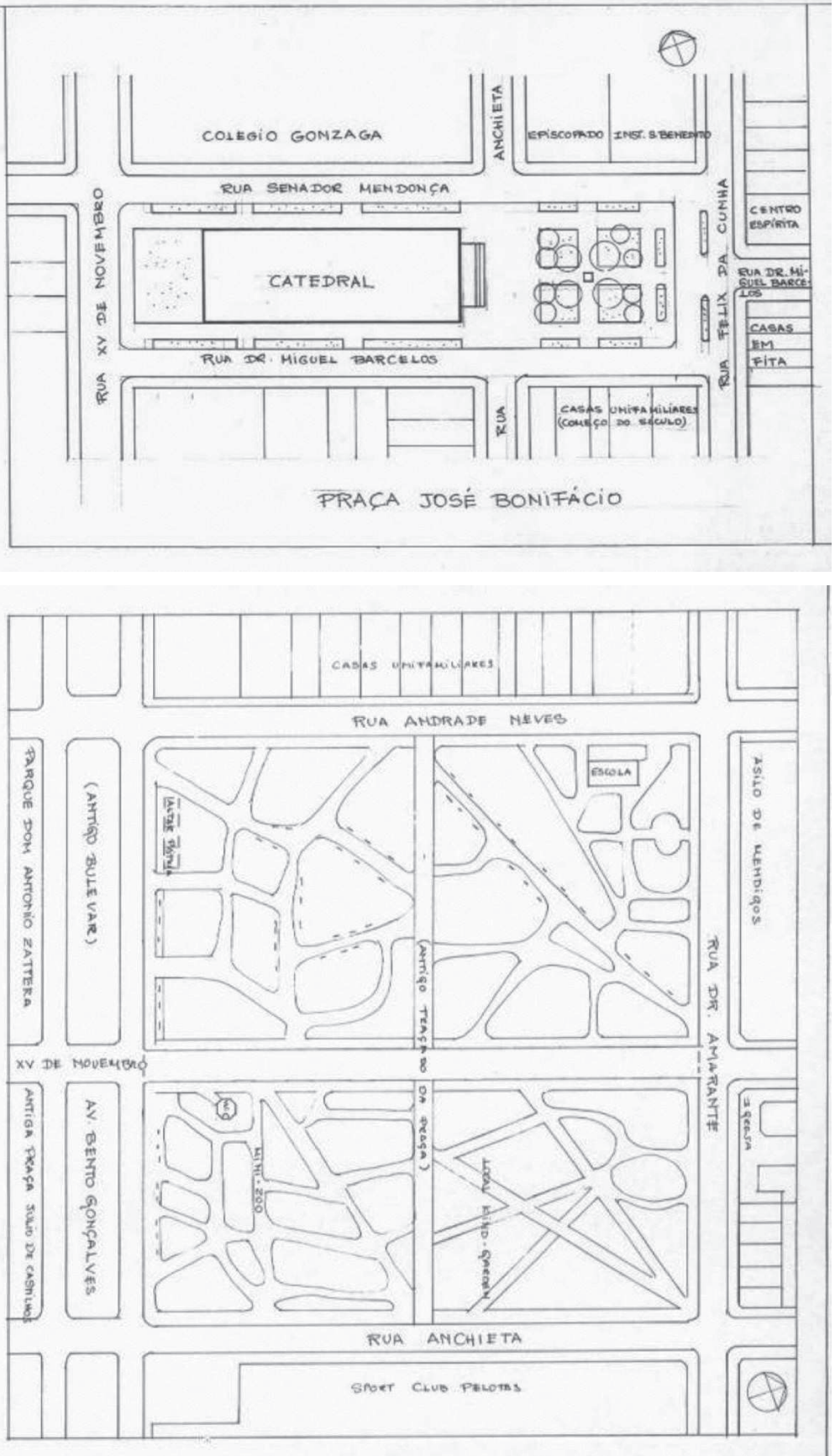

Figura 6: Planta baixa da praça José Bonifácio

Fonte: Levantamento local da autora. Desenho de Joana Paradeda, 2003

Figura 7: Planta baixa da praça Júlio de Castilhos

Fonte: Desenho de Joana Paradeda, baseado em plantas de 1909

sava-se que um local com muitas árvores era ideal para a saúde, uma vez que o ar seria mais puro. Desde que foi saneada e ajardinada, ela teve objetivos principais a recreação infantil e a educação, contemplando uma faixa etária bem determinada, a da criança. Essa praça se diferenciou das outras praças pelotenses pelo número de construções dentro do mesmo espaço público, voltados principalmente para a educação.

Mudando o eixo em $90^{\circ}$, tem-se a praça Piratinino de Almeida ou da Santa Casa, como é chamada, cuja finalidade sempre foi de suporte para o hospital e local para a caixa d'água, monumento marcante dentro da cidade. Seu traçado foi cuidadosamente elaborado e ajardinado, pois era de importância vital ter um belo jardim público emoldurando o prédio principal do hospital e do qual tanto os pelotenses se orgulhavam. Sempre foi uma praça de poucos equipamentos e com duas finalidades bem determinadas: a de servir de ante-sala para o hospital e de abastecimento para cidade. Sua finalidade de abastecer a cidade permanece até hoje; a outra, não mais existente. 


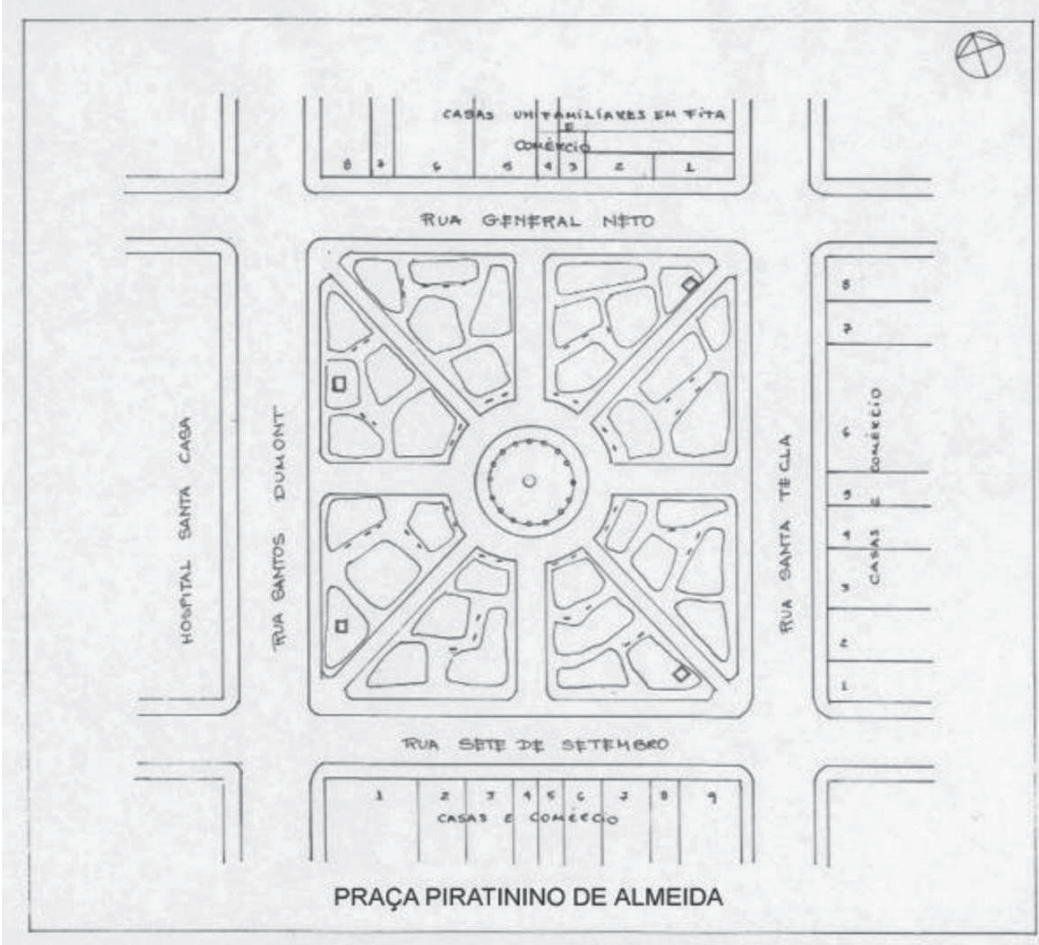

Figura 8: Planta baixa

Fonte: Levantamento da autora. Desenho de Joana Paradeda, baseado em plantas atuais da prefeitura

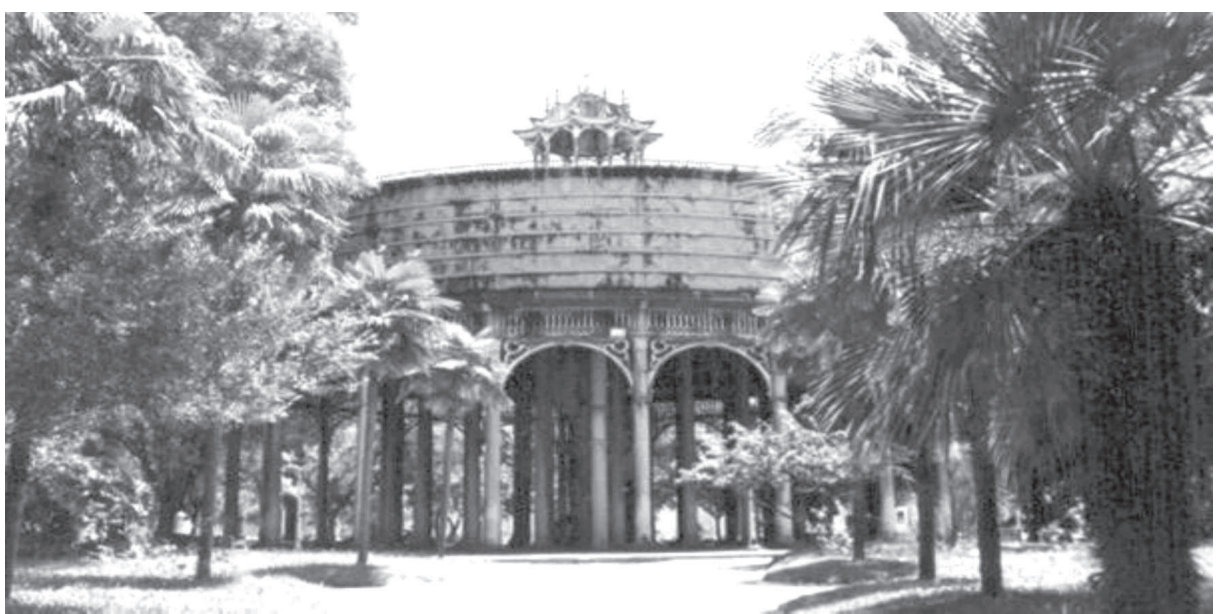

Figura 9: Caixa d'água de ferro Fonte: Fotos de Neco Tavares, 2000

A praça Cipriano Barcelos ou, como é chamada popularmente, praça dos Enforcados é portadora de um nome, cuja simbologia é bastante forte. Quanto à sua organização espacial, é enriquecida por uma alameda de palmeiras que levam ao ponto central da praça onde se encontra um chafariz. É a única das cinco praças que possui essa marcação, tão utilizada hoje, mas que, para a época, era um fato inédito. Essa praça e as áreas que the são periferias já serviram de local para enforcamentos, para batuques e de área de "escape" para as águas do arroio Santa Bárbara. Hoje está legada ao esquecimento e ao descaso.

A influência cultural exercida pelos países europeus, a necessidade da cidade conectar-se a uma nova ordem social, econômica e política pela qual o país passava na transição do século XIX ao século $X X$, quando as cidades passaram de império para republicanas, proporcionaram o surgimento de campanhas de modernização, de salubridade e de embelezamento das cidades, e o modo mais eficiente para essa demonstração era através do cuidado com seus espaços públicos abertos, pois eles, a princípio, poderiam ser utilizados por todos, sem descriminação de raças ou de poder econômico, demonstrando uma civilidade e uma modernidade tão valorizadas pelo novo regime. 


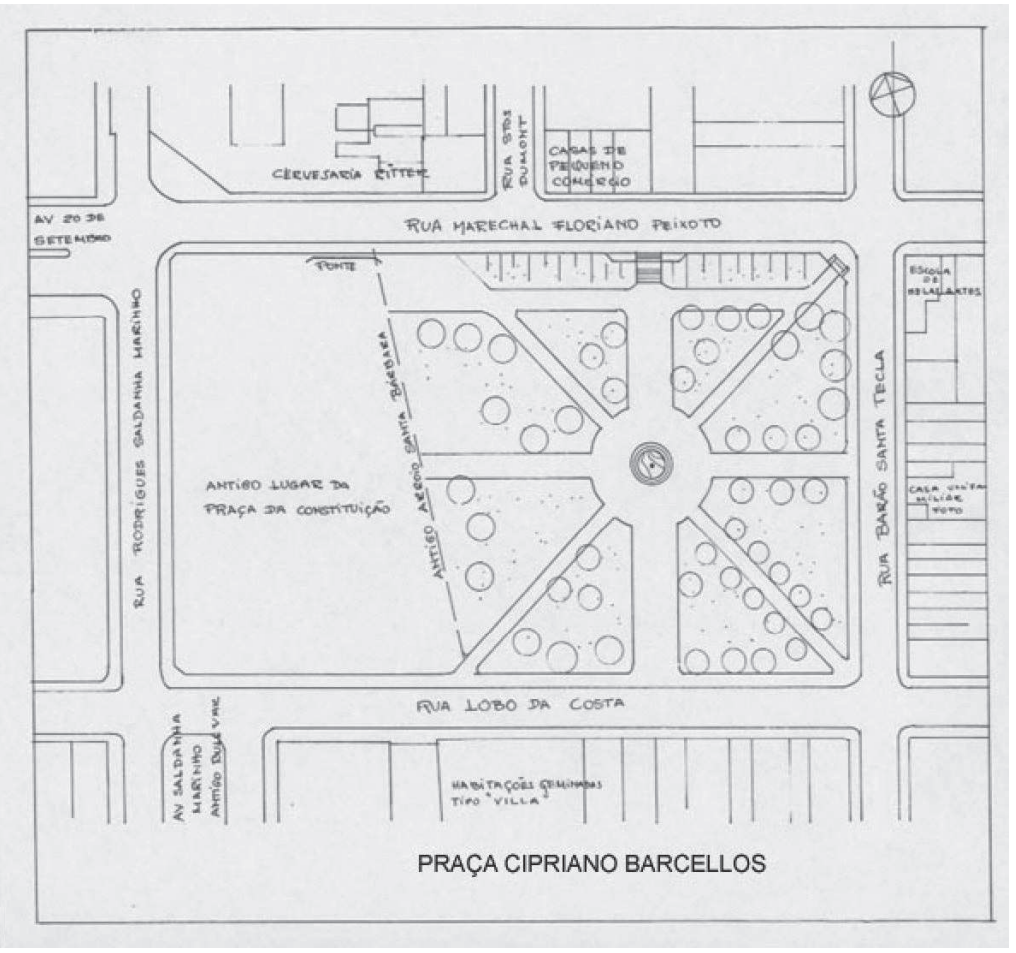

Figura 10: Planta baixa da praça Fonte: Desenho de Joana Paradeda, baseado em plantas atuais da prefeitura, 2003

Surge uma nova tipologia urbana: as praças ajardinadas. Com assimilação do modelo da praça ajardinada como padrão de modernidade urbana, consolidou-se o hábito de planejar e projetar as praças públicas, principalmente as centrais da cidade.

A praça passou a ser um belo cenário ajardinado, com finalidades bem diversas das praças coloniais. Ela é destinada às atividades de recreação, para o lazer contemplativo, para os atos de sociabilidade da população e para os passeios, ato de ser visto e de ver os outros.

O uso da vegetação nas praças tem como ponto focal a forma de amenizar os efeitos de urbanização intensa dos centro urbanos, trazendo a natureza domesticada para junto dessa população, que não tem mais contato direto com essa natureza.

As praças são redutos da natureza dentro da malha urbana. A expansão rápida das cidades rompeu com sua estabilidade e, conseqüentemente, com seus espaços, que agora possuem usos diversos.

As edificações representativas e relevantes para a memória histórico-urbana, localizadas ao redor das praças, foram substituídas por outras, destruindo esse elo entre o passado e o presente.

A arquitetura da paisagem é modificada a cada instante, por causa dessas mudanças, perdendo seus significados.

Preservar e valorizar esses espaços não significa congelar o passado, mas possibilitar que a cidade se desenvolva de acordo com suas necessidades atuais, incorporando as mudanças e, ao mesmo tempo, guardando suas características particulares.

\section{Notas}

240 (1) ZUCKER, Paulo. Town and square: From the Ágora to the village green. Nova York: Columbia University Press, 1959, p. 1.

(2) HALBWACHS, Maurice apud LEPETIT, Bernard. Por uma nova história. São Paulo: Edusp, 2001, p. 147-153.

(3) Id., ibid., 2001, p. 148-149. 
(4) SANTOS, Carlos Alberto Ávila. Espelhos, máscaras, vitrines: História urbana. São Paulo: Edusp, 2002, p. 36-37.

(5) NEVES, Margarida de Souza. História da crônica. Crônica da história. Rio de Janeiro: Ed. José Olympio, 1995, p. 17.

(6) CULLEN, Gordon. Paisagem urbana. Lisboa: Ed. 70 Ltda., 1971, p. 14.

(7) MARIN, Louis. Sublime, Poussin. São Paulo: Edusp, 2000, p. 27-28.

\section{Bibliografia}

AGACHE, Alfred. Cidade do Rio de Janeiro: Extensão - remodelação - embelezamento. Paris: Foyer Brasilien.

ANJOS, Marcos Hallal dos. Estrangeiros e modernidade: A cidade de Pelotas no último quartel do século XIX. Pelotas: UFPEL, 2000.

AUGE, Marc. Não-lugares: Introdução a uma antropologia da supermodernidade. São Paulo: Papirus, 1994.

BAUMER, Franklin L. O pensamento europeu moderno. Séculos XIX e XX. Rio de Janeiro: Edições 70 Ltda., 1977.

CENTENO, Yvette; KACE, Freitas de Lima (Coord.). A simbólica do espaço: Cidades, ilhas, jardins. Lisboa: Ed. Estampa, 1991.

$\mathrm{CHOAY}$, Françoise. A natureza urbanizada. A invenção dos "espaços verdes". A cidade, arte e arquitetura na Europa 1870-1993. Paris: Centro Pompidou, 1994.

CULLEN, Gordon. Paisagem urbana. Lisboa: Edições 70 Ltda., 1983.

HALBWACHS, Maurice. La mémorie collectiva. Paris, 1950.

LEPETIT, Bernard. Por uma nova história urbana. Organização de Heliana Angotti Salgueiro. São Paulo: Edusp, 2001. MACEDO, Sílvio Soares; ROBBA, Fábio. Praças brasileiras. São Paulo: Edusp, 2002.

MAGALHÃES, Mário Osório. História e tradições da cidade de Pelotas. Porto Alegre: IEL/UCS, 1981.

MARIN, Louis. Sublime Poussin. São Paulo: Edusp, 2000.

MUNFORD, Lewis. A cidade na história: Suas origens, transformações e perspectivas. São Paulo: Martins Fontes, 1982.

NEVES, Margarida Souza; REZENDE, B. (Org.) Cronista do Rio de Janeiro. História da crônica. Crônica da história. Rio de Janeiro: José Olympio, 1995.

SANTOS, Carlos Alberto Ávila. Espelhos, máscaras, vitrines: Estudo iconológico de fachadas arquitetônicas - Pelotas (1870-1930). Pelotas: Educat, 2002.

SEGAWA, Hugo. Ao amor do público: Jardins no Brasil. São Paulo: Studio Nobel, 1996.

ZUCKER, Paul. Town and square: From the Agora to the village green. Nova York: Columbia University Press, 1959. 